This item was submitted to Loughborough's Research Repository by the author.

Items in Figshare are protected by copyright, with all rights reserved, unless otherwise indicated.

\title{
Comparison of two tracer gas dilution methods for the determination of clothing ventilation and of vapour resistance
}

PLEASE CITE THE PUBLISHED VERSION

PUBLISHER

(c) Taylor \& Francis

VERSION

AM (Accepted Manuscript)

LICENCE

CC BY-NC-ND 4.0

\section{REPOSITORY RECORD}

Havenith, George, Ping Zhang, Kent Hatcher, and Hein A.M. Daanen. 2019. "Comparison of Two Tracer Gas Dilution Methods for the Determination of Clothing Ventilation and of Vapour Resistance". figshare. https://hdl.handle.net/2134/5596. 
This item was submitted to Loughborough's Institutional Repository (https://dspace.lboro.ac.uk/) by the author and is made available under the following Creative Commons Licence conditions.

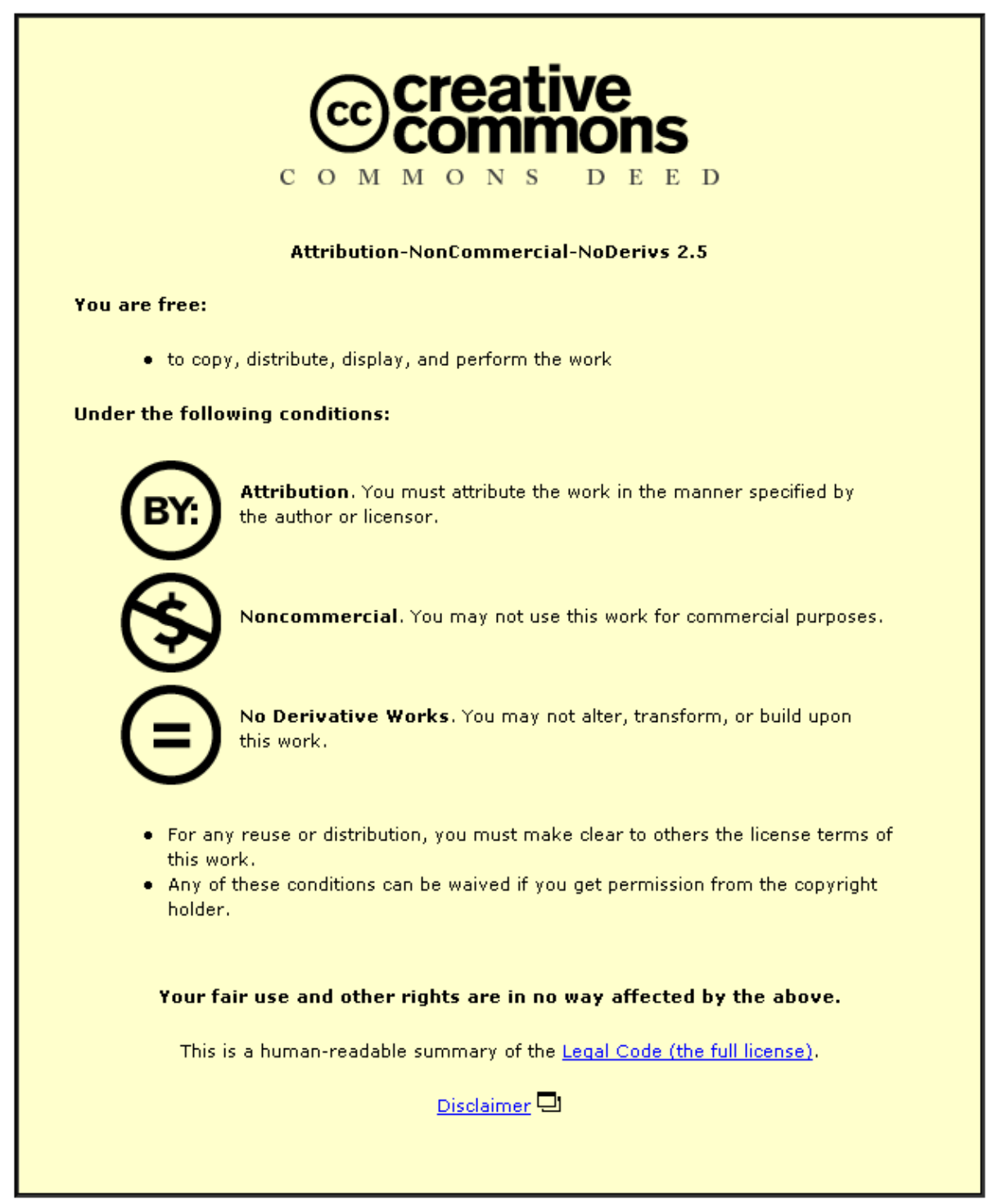

For the full text of this licence, please go to: http://creativecommons.org/licenses/by-nc-nd/2.5/ 
November 10, 2009

\title{
COMPARISON OF TWO TRACER GAS DILUTION METHODS FOR THE DETERMINATION OF CLOTHING VENTILATION AND OF VAPOUR RESISTANCE
}

\author{
George Havenith ${ }^{1}$, Ping Zhang ${ }^{1}$, Kent Hatcher ${ }^{1,2}$ and Hein Daanen ${ }^{2}$ \\ ${ }^{1}$ Environmental Ergonomics Research Centre, Dept. of Ergonomics (Human Sciences), \\ Loughborough University, Loughborough, LE11 3TU, UK \\ ${ }^{2}$ TNO Defence and Security, Soesterberg, NL
}

Corresponding author:

Prof. George Havenith

Dept. of Human Sciences,

Loughborough University,

Loughborough,

LE11 3TU, UK

G..Havenith@lboro.ac.uk

$+441509223031$

FAX +44 1509223940

Author Posting. (c) 'Taylor and Francis', 2010.

This is the author's version of the work. It is posted here by permission of Taylor and Francis for personal use, not for redistribution.

The definitive version was published in Ergonomics, Volume 53 Issue 4, April 2010.

doi:10.1080/00140130903528152 (http://dx.doi.org/10.1080/00140130903528152) 


\section{ABSTRACT}

Two methods for Clothing microclimate ventilation determination (Crockford (CR), 1972 and Lotens \& Havenith (LH), 1988) are compared for reproducibility, validity, and usability. Both methods showed good sensitivity and reproducibility (average coefficient of variation 1.5$2.3 \%$ for the method, up to $7 \%$ for method and dressing/movement effects combined) and produce values close to calibration values in forced ventilation tests $(r=0.988)$. Weak points for $\mathrm{CR}$ are limits in time constant of the equipment, causing an upper limit of measurable ventilation (around $800 \mathrm{l} / \mathrm{min}$ ), and the measurement of clothing microclimate volume, showing large errors. Alternatives (whole body scanner or manual circumference measurements) were shown to produce good results. For $\mathrm{LH}$, the distribution of the tracer gas over the whole skin surface becomes a problem factor at very high ventilations (above $1000 \mathrm{l} / \mathrm{min})$.

When the measurement is used to determine water vapour resistance, the choice of tracer gas $\left(\mathrm{O}_{2}, \mathrm{Ar}, \mathrm{CO}_{2}, \mathrm{SF}_{6}\right)$ affects results. 


\section{ABSTRACT}

Clothing microclimate ventilation is an important parameter in climatic stress and in contaminated environments. The two main methods for its determination (Crockford (CR), 1972 and Lotens \& Havenith (LH), 1988) are, after further development, compared in terms of reproducibility, validity, and usability. Both methods are shown to have a good sensitivity and reproducibility (average Coefficient of Variation 1.5-2.3\% for the method, up to $7 \%$ for method and dressing/movement effects combined) and produce values very close to calibration values in forced ventilation tests $(r=0.988)$. Weak points for $C R$ are the limits in the time constant of the measurement apparatus, causing an upper limit of ventilation that can be reliably measured (around $800 \mathrm{l} / \mathrm{min}$ ), and the for this method required measurement of clothing microclimate volume. The original 'vacuum oversuit' method was cumbersome and prone to large errors. Alternatives (whole body scanner or manual circumference measurements) were shown to produce good results. For $\mathrm{LH}$, the distribution of the tracer gas over the whole skin surface becomes a problem factor at very high ventilations (above $1000 \mathrm{l} / \mathrm{min})$.

As all methods use tracer gasses $\left(\mathrm{O}_{2}, \mathrm{Ar}, \mathrm{CO}_{2}, \mathrm{SF}_{6}\right)$ with diffusivities smaller than that of water vapour, this potentially creates a problem in the calculation of vapour resistance from the ventilation values in the region where the emphasis of vapour transfer moves from diffusion to convection. In most real life situations, where body and air movement are present, a correction is not required however as the error remains below $10 \%$.

Keywords: Clothing Ventilation, Vapour resistance, tracer gas, Clothing Microclimate Volume

\section{Statement:}

Clothing Ventilation indicates heat loss potential as well as risk of pollutants entering the clothing. Two main methods for its determination are compared and validated, identifying a number of issues. The results allow an in depth analysis of the pros and cons of the available methodologies. 


\section{INTRODUCTION}

Clothing microclimate ventilation impacts worker's health and safety in different ways. Particularly in the heat it determines the person's cooling as it transports water vapour (evaporated sweat) and heat away from the skin (Fetcher et al., 1949, Havenith et al., 1999, 2002, Caravello et al., 2009). In indoor environments it will affect thermal comfort (Harter et al., 1981, Shivers et al., 1977, Vokac et al., 1973). In the cold, at low activity it can induce hypothermia due to heat lost. In contaminated environments, it can transport environmental contaminations into the clothing microclimate and create a hazard to the worker (Bittel et al., 1992, Havenith et al., 1999). Clothing ventilation is thus an important parameter in clothing design and evaluation (Vokac et al., 1973, Birnbaum and Crockford, 1978, Ghali et al., 2002, 2009). Furthermore, clothing micro climate ventilation is strongly linked to the 'real life' vapour resistance $\left(R_{e}\right)$, as measured on sweating manikins and human subjects (Havenith, 2005). The $R_{e}$ is defined by the combination of diffusion of vapour through the fabrics (as measured e.g. on a 'skin model' apparatus, ISO 11092) and the ventilation (convection) of microclimate air (between skin and clothing) by environmental air through openings and fabrics. As determination of $R_{e}$ of clothing ensembles is currently quite complex (ISO 9920), time consuming and costly, alternative methods need to be developed. Deduction of $R_{e}$ from clothing microclimate ventilation measurements may provide a simpler and possibly cheaper alternative, as shown by Havenith et al. (1990) and this could therefore be a secondary use of clothing ventilation measurements. In addition, the study of clothing ventilation allows researchers to separate the different pathways (diffusion versus convection or through openings versus through fabric) for heat loss through clothing (Havenith et al. 2008).

Two methods for measuring clothing ventilation have been developed in the past: one by Crockford et al. (1972) [CR] and one by Lotens and Havenith (1988) [LH], both using tracer gases to replace water vapour. $\mathrm{CR}$ first floods the microclimate with Nitrogen $\left(\mathrm{N}_{2}\right)$ and then looks at the re-entry of Oxygen $\left(\mathrm{O}_{2}\right)$ when the $\mathrm{N}_{2}$ supply is closed; LH brings a continuous flow of Argon (Ar; in initial testing Nitrous Oxide was used) in the microclimate and looks at the steady state dilution of the tracer gas in the microclimate. Both methods for measuring clothing ventilation are currently in use in different laboratories (Holland et al., 1999, Havenith et al., 1990, 1996, Ueda et al., 2005 ${ }^{\mathrm{a}, \mathrm{b}}$, 2006, Ghaddar et al., 2005, Satsumoto et al. 2010) however without ever being directly compared and with only limited validation. A third method was developed by Reischl et al. $(1980,1987)$, however as this is only for local ventilation values this is not considered in this project.

The objectives of this research project were:

- $\quad$ To evaluate the available methods, and where possible make simple improvements.

- $\quad$ To compare the two methods available (validity, reproducibility etc).

- To investigate the usability of both methods for the determination of clothing vapour resistance.

- To investigate the limits of the validity range of these methods in relation to the relative 
contribution to total mass transport by convective mass transport and diffusion mass transport.

\section{METHODS}

The two methods for the determination of clothing ventilation were:

\subsection{Crockford method}

The ventilation of the skin micro-climate $\left(\dot{\mathrm{V}}_{\mathrm{MC}}\right)$ is determined from separate measurements of the micro-climate volume and the air exchange rate, as originally described by Crockford et al. (1972, 1974), Birnbaum \& Crockford (1978) and further developed by Sullivan et al. (1987), Angel (1995), and Bouskill et al. (1999, 2002):

Micro-climate ventilation $\left(\dot{\mathrm{V}}_{\mathrm{MC}}\right)=$ Micro-climate Volume $(\mathrm{MCV}) \cdot$ Air Exchange Rate $\quad\left(\mathrm{I} . \mathrm{min}^{-1}\right)$

Micro-climate volume (MCV) is measured using a light-weight, flexible, 1-piece, air-impermeable oversuit (Tyvek), sealed at the neck, which encloses the whole body surface area including the hands and feet, over the test ensemble. Air is evacuated from the oversuit via a tubing system placed on the skin, until it lays just on top of the test ensemble and thus changes the clothing micro-climate pressure, as measured on a pressure sensor attached to a second perforated tubing system on the skin. Micro-climate volume is defined as the air volume evacuated from this point until the ambient to clothing micro-climate pressure difference reaches $-30 \mathrm{~cm} \mathrm{H}_{2} \mathrm{O}$ (i.e. all air evacuated from clothing). Triplicate measurements are made and the mean value calculated. Between measurements the oversuit is opened and the clothing readjusted to original drape. Micro-climate volumes are measured at ambient temperature, pressure, dry (ATPD).

With the air-impermeable oversuit removed, air exchange rate next to the body surface is measured by gas dilution. The oxygen concentration in the micro-climate is measured continuously (fast response Oxygen sensor, e.g. Servomex, AO580, Taylor Instruments Ltd, Crowbrough, UK) using a sampling harness (thin perforated tubing) covering the whole clothed body except hands, feet and head. Nitrogen $(100 \%)$ is then flushed throughout the micro-climate, using a distribution harness (a perforated tubing system covering the skin), until the oxygen concentration next to the skin surface drops below $10 \%$. The Nitrogen supply is then closed and the development of the Oxygen concentration in the microclimate is registered. The shape of the Oxygen concentration curve after the Nitrogen supply is closed is then used (assuming a first order system; Bentley et al., 2000) to calculate the air exchange rate according to the model:

$$
p(t)=p_{\text {air }}-p_{1} \cdot e^{-r \cdot t}
$$

where:

$p(t) \quad$ is the concentration of oxygen in the clothing microenvironment (\%) at time $t$, 
$\begin{array}{ll}p_{\text {air }} & \text { is the concentration of oxygen in the surrounding air } \quad(\%), \\ p_{1} & \text { is such that } p_{\text {air }}-p_{1} \text { is the initial concentration of oxygen in the clothing microenvironment at } t=0\end{array}$ $(\%)$,

$r \quad$ is the rate of air exchange $\left(\mathrm{min}^{-1}\right)$.

Observed oxygen return curves showed a good fit with the single exponential model used.

Typically the first part of the oxygen re-entry curve (first $2 \%$ increase) is discarded as this is affected by the switch-over process.

\subsection{Lotens and Havenith method}

In 1988, Lotens and Havenith and later Havenith et al. $(1990,1996,2003)$ modified the original Crockford method. With this method, diluted Argon (2-15\%; other gasses may be used too) is injected at the skin at numerous locations distributed over the body (except head, hands, feet) using a perforated tubing system. At similar locations, an equal volume gas sample of the clothing microclimate air is taken. Ventilation is calculated as:

$$
\text { Microclimate Ventilation }(\mathrm{l} / \mathrm{min})=\dot{\mathrm{V}}_{\mathrm{MC}}=\frac{C_{\text {in }}-C_{\text {out }}}{C_{\text {out }}-C_{\text {air }}} \cdot \text { circulating flow }
$$

With:

$\mathrm{C}_{\text {in }}=$ Tracer gas concentration blown into the garment

$\mathrm{C}_{\text {out }}=$ Tracer gas concentration in sample taken from microclimate

$\mathrm{C}_{\text {air }}=$ Tracer gas concentration in environment (background)

Circulating flow=volume of air circulated by the measuring system

The tubing system is designed to take equivalent samples at the different body parts. Both injected and sampled gasses are analysed for their Argon concentration using a mass spectrometer (Spectra Minilab, Crewe, UK). The dilution factor of the gas in the clothing microclimate at the skin is a measure of clothing microclimate ventilation, and can be used to calculate clothing vapour resistance (Havenith et al., 1990). In comparison to earlier systems (Lotens and Havenith, 1988; Havenith et al., 1990), the tubing distribution and sampling system was upgraded to: -have equivalent distribution of perforations in both distribution and sampling harnesses, -an increased amount of tubing to get a better distribution over the skin, -all sampling connection to the mass spectrometer were moved to the positive pressure side of the circulation pump, thereby reducing the effect of pressure differences between inlet and outlet on the mass spectrometer values.

Instead of a mass spectrometer other (cheaper) gas analysers may be used in combination with other tracer gasses, e.g. $\mathrm{O}_{2}, \mathrm{CO}_{2}$ or $\mathrm{SF}_{6}$, though the type of tracer gas can affect the measurement as will be discussed later.

Both CR and LH exclude head, hands and feet from the measurements, i.e. the 'unclothed' areas. 
Hence all results shown in this paper apply to the clothed areas only. Where vapour resistances are calculated from the ventilation data, this also then applies to the clothed areas. For the calculation of whole body vapour resistance, a parallel resistance calculation needs to be used (Havenith, 2005), using an estimated vapour resistance for head hands and feet, which can be obtained from literature.

\subsection{Comparing the systems}

In their application, the methods will typically be used on humans in various clothing with different types/levels of movement and air speed. This will introduce various sources of variance in the measurement, as e.g. a human will change posture, clothing fit/drape, movement and e.g. angle towards wind with each exposure. For a comparison of both systems it was therefore decided to perform three series of experiments, trying to break down this variance:

- $\quad$ Series one used a shop manikin (no movement, fixed shape and posture) to wear a 2 piece, air impermeable ensemble and used a defined forced ventilation of the microclimate air. The methods should ideally produce the same ventilation values as those introduced (direct validation). A tubing system that distributes air into the clothing microclimate over the different body parts was attached to a blower, and the air volume introduced measured by a calibrated dry gas meter (Cranlea, UK; below 200 I/min) or a pneumotachograph (Fleisch, F+G Instruments, Hechingen, Germany; $>200 \mathrm{l} / \mathrm{min})$.

- Series two used again a shop manikin (static), but now varied the clothing. Clothing with 4 levels of air permeability (AP) was chosen: Impermeable (coated rainwear), low AP (open weave track suit under densely woven track suit), Medium AP (densely woven tracksuit) and High AP (open weave track suit) and tested in 3 wind speeds $(0.1,0.7$ and $4.0 \mathrm{~m} / \mathrm{s}$ ) (comparison of systems in practical application on static system).

- Series three worked with human subjects that stood or walked at different speeds $(0.7$ and $4.0 \mathrm{~m} / \mathrm{s})$ in different winds $(0.1,0.7$ and $4.0 \mathrm{~m} / \mathrm{s})$ and wore the same clothing as in series two (comparison of systems in practical use on a dynamic system).

All ventilation measurements were repeated a minimum of four times for each condition.

A separate validation of the MCV measurement was undertaken (Hatcher, 2001, Daanen et al., 2002). In order to test the validity of the MCV determination, other available methods for this purpose needed to be identified. These were: 1: Determining MCV using a model based on circumference measurements of all body parts, nude and clothed (based on Lotens and 
Havenith, 1991; see Fig. 1) and 2: Determining MCV using a whole body scanner system, subtracting nude from clothed volume (see Fig. 2).

For a proper validation, a gold standard method is required. The scanner method was considered to be the gold standard for this purpose after extensive testing (Brandsma, 2001, Lee et al., 2007, Tan and Daanen, 1999). A whole body laser scanner (Vitronic Vitus Pro scanner and Polyworks software) was used to determine the MCV. The scanner uses 16 camera's to determine the shape of the subject and 4 cameras for the colour texture. The resolution of the scanner is approximately $3 \mathrm{~mm}$. The volume under the garment was determined by subtracting the volume of the semi-nude body from the volume of the scan with the garment. Figure 2 shows a frontal and transversal view of the scans for a subject. Two garments (T-shirt only and a Coverall) were measured on 4 subjects with one repetition each.

\section{RESULTS}

\subsection{Ventilation}

Table 1 shows the results of the repeatability tests, providing the average Coefficient of Variation ( $\mathrm{CV}=$ standard deviation (SD)/mean*100\%) values and their ranges for the different experiments on ventilation measurement. For the Crockford method tests, this CV only represents the variation in the ventilation (i.e. tracer gas) tests, as it has used a single value for the clothing microclimate volume of each ensemble in the calculation. Hence, the CV for the method as a whole will be larger when the CV for this volume determination is included. As the LH test does not require this value, its CV's represent those for the complete method. Overall, both methods' CV's are of similar magnitude, with a clearly higher CV for the Crockford method only in the condition of human participants, standing in wind.

Table 1 about here.

Figure 3 shows the results of the comparison between measured ventilation values and the artificially induced, forced ventilation. Ideally points should be on the line of identity, except for the lowest values where the natural ventilation (natural convection) would remain while the forced ventilation would be reduced to zero. Data above and below $200 \mathrm{l} / \mathrm{min}$ are presented separately as the equipment used was different and to allow detail at lower values to be visible. Both method's data show a strong, significant, relation with the actual forced ventilation ( $r=0.988$ and 0.998$)$, and both relations are close to unity for low ventilations ( $<200 \mathrm{l} / \mathrm{min}$ ). Only at the lowest value (no ventilation) a difference between both methods is evident, in that the LH method levels off around $30 \mathrm{l} / \mathrm{min}$, whereas the $\mathrm{CR}$ method goes 
down to about $6 \mathrm{l} / \mathrm{min}$. These baseline values should reflect the baseline ventilation of the ensemble in static conditions.

In an absolute sense, in the range below $200 \mathrm{l} / \mathrm{min}$, the CR system slightly overestimates the ventilation (though a problem with the micro-climate volume determination may also be present; to be discussed later), whereas the LH system slightly underestimates it. At the very high values (above $800 \mathrm{l} / \mathrm{min}$ ) the methods clearly diverge. The CR method's measurement starts to level off, whereas the LH system starts to slightly overestimate the ventilation.

Fig 4 shows the ventilation results for both methods in relation to each other for a number of different ensembles (series two and three). A clear difference between garments is visible, and a difference between manikin and human subject data: CR data being higher than LH data for the human, while the reverse is true for the manikin.

\subsection{Microclimate Volume determination}

Data presented above for $\mathrm{CR}$ was calculated using a single value for microclimate volume (MCV), and thus do not represent variations/errors that may be caused by this part of the $\mathrm{CR}$ method. The error and variance in MCV was investigated separately. Figure 5 provides the mean and standard deviation results of the MCV determination with the three methods used. It is evident that considerable differences exist in MCV between the three investigated methods. The scanner gave the highest values, with the highest reproducibility $(C V=14 \%)$. The vacuum suit method was deemed very time consuming and error prone ( $C V=30 \%)$, due to the occurrence of leakages (tests were leakage was evident were excluded) and the difficulty determining the exact moment where the outer suit touches the clothing. Analysis of the results for the different garments showed that the vacuum oversuit method's results seemed more consistent for low permeability clothing, but for permeable clothing it seems that the air outside and inside the clothing may be evacuated simultaneously, thereby lacking clear markers in the measured microclimate pressure. For the model calculations, the CV was $17 \%$. The average results were similar for the vacuum suits and the model values, but these were both about $15 \%$ lower than the scanned values. Differences in volume within subjects over 3 repetitions were $1 \%$ for the scanning method, $3 \%$ for the model and $8 \%$ for the vacuum suit. 


\section{DISCUSSION}

\subsection{Reproducibility}

The CV data in Table 1 can be used to assess the methods' reproducibility. As expected, the $\mathrm{CV}$ is smallest for the most controlled condition (forced ventilation) and increases when more sources of variation are introduced. For the forced ventilation (experiment one), in absence of other factors producing 'noise', the method itself is the main source of variation and low CV's of 1.5 and $2.3 \%$ respectively are observed. This increases to $3.4 \%$ on the static manikin (wind causing the ventilation) and 5.0 to $8.0 \%$ on the human, when variability due to dressing, external conditions and subject behaviour is added. As the same CV's are observed when the ventilation is expressed as vapour resistance (Havenith et al. 1990), this reproducibility can be considered very good, as it is comparable to other methods for determination of clothing vapour resistance (e.g. on thermal manikins or subjects; see ISO 9920, 2007 and Richards and McCullough, 2005). Differences between methods are minor, though as mentioned earlier, these numbers do not include the additional variance caused by determination of the MCV in the Crockford method.

The CV is typically highest for standing still in higher wind speeds (9.1-13.7\%), reflecting the actual variability in ventilation that can be expected in such conditions. Adding body movement 'stabilizes' the measurements ( $\mathrm{CV}=7.1-8 \%)$ as observed before by Havenith et al. (1990).

\subsection{Validity}

\section{Forced ventilation}

The validity of the methods (i.e. 'does it really measure ventilation') was tested by using a forced ventilation system. If the methods are valid, the measured ventilations should show a relation with the introduced forced ventilation, preferably a one-to-one relation. With observed correlations of 0.988 and 0.998 it is evident that the methods are valid in this respect. Furthermore, the fact that both relations are close to unity for low ventilations $(<200$ I/min) strengthens this conclusion.

An issue seems present at very high ventilations. The CR method's measurement starts to level off, whereas the LH system starts to overestimate the ventilation. Analyses of the systems' properties shows that for the CR system, the time constant for the $\mathrm{O}_{2}$ re-entry in the microclimate starts to approach the actual measuring system's time constant ( time lag in tubing, valve response, oxygen sensor response), so apparently the limit of the current equipment design is reached. This may be improved by changes to the circulating sample 
flow (higher flow $\rightarrow$ lower lead time), faster response oxygen sensor etc. As the LH system works on equilibrium concentrations of Argon, no time constant problem is present here. The overestimation observed at high ventilation rates is most likely due to gas distribution problems. At these high ventilation values, the gas from the gas distribution tubes does not 'reach' the sample tubes before being ventilated out of the garment, giving a high value for ventilation in the calculation. Improvement here would require a more densely distributed distribution/sampling system to ensure an even tracer gas distribution, even at high ventilation rates. As will be shown later, such high ventilation values only occur in extremely air permeable garments in high winds.

\section{Microclimate Volume determination}

It is important to note that the data presented above for CR was calculated using a single value for microclimate volume (MCV), and thus does not include variations/errors that may be present in this part of the method. That such variance and/or error is indeed present was evident in the observations (Fig. 5). Especially the vacuum suit, so far the main method used in $\mathrm{CR}$ for determination of MCV, presents a number of error sources. They are vulnerable to leaks, with small leaks invalidating the volume measurement; they are very uncomfortable for the participants to wear (tight neck seal; warm) and for permeable clothing it was extremely difficult to pinpoint the moment where the air outside the clothing is removed and the microclimate evacuation starts. From the experience gained in the present and earlier (Bouskill et al., 1999, 2002) testing it is concluded that MCV should preferably be determined by a 3D scanning method (though still time consuming due to the need for manual corrections in the dataset to obtain a 'closed volume'). Where not available, the model method should be used, as it performed well and had fewer technical problems than the vacuum method.

For the overall error in the CR method, these results imply that the actual total errors are significantly higher than those shown in Table 1, especially when using the traditional vacuum oversuit air evacuation method.

\section{Sensitivity}

In the evaluation of sensitivity, one needs to discriminate again between the experimental conditions in terms of source of variability. Where the ventilation is highly defined and constant (forced ventilation) the sensitivity and discriminative power of both methods is high. Fig 3 illustrates that differences of $10 \mathrm{l} / \mathrm{min}$ can be easily determined at a statistically significant level. When more sources of variation are introduced however, the discriminative 
power reduces due to the higher variability in the actual ventilation values within each condition (caused e.g. by small posture or dressing changes).

Analyses of the human subject (=real life) data (experiment 3 ) for statistically just detectable differences $(p=0.05)$ with the actually observed variance showed that these typically lie around 1.1 to 1.5 times the size of the CV for 6 repeated measurements and around 2 to 4 times CV for 3 repeated measures, with the higher ratio at low ventilations. Given the observed CV's, this indicates that the difference between 2 conditions needs to be 5 to $8 \%$ of the ventilation value for no wind, and up to 10 to $20 \%$ for the high wind speed, all based on $n=6$. LH will provide a higher sensitivity than $\mathrm{CR}$ if all sources of error (including the MCV determination) are considered.

\subsection{Application}

The data presented in Figure 4 demonstrates the practical application of the methods in experiments. As expected, the human subject test showed more variability than the manikin tests (Table 1 ) due to the introduction of posture and movement variation. A clear difference between garments is visible, and a difference between manikin and human subject data: $\mathrm{CR}$ data being higher than LH data for the human, while the reverse is true for the manikin. Given the problems with the MCV (it was found that the MCV for the humans determined in the present tests was much higher than literature data, and the latter showed high variability (>70\%) between studies for similar ensembles (Bouskill, 1999)), and the observed discrepancy between manikin MCV and human MCV (MCV's obtained for the manikin were much lower than those for the subject, whereas this was not reflected by their shapes), it was decided, given the comparable shape and size of the manikin and the human participants, to set the MCV equal for both and to derive its value from the measurements, combined with the scanner data and literature values. To test the principal effect, all MCV's for each of the 4 clothing types were set to the same value, resulting in new ventilation values for CR (Fig. 6). It is evident that differences between manikin and subject now have disappeared, as do most suit differences between the methods, providing strong indication that indeed the MCV was the underlying cause for the deviations between suits, wearers and methods.

Additional observations are that the $\mathrm{CR}$ ventilation initially exceeds the $\mathrm{LH}$ ventilation, but this reverses above ventilations of $\pm 600 \mathrm{l} / \mathrm{min}$. The first can be attributed to the choice of $\mathrm{MCV}$, as this directly affects the slope of the line (ventilation for the Crockford method is linearly related to $\mathrm{MCV}$ ). Given the forced convection results of experiment 1 (CR method giving slightly higher values than $\mathrm{LH}$ ), this result seems consistent. 
The second point, the levelling off of the CR method compared to the LH method is again consistent with the forced convection data of Fig. 3.

\subsection{Diffusion versus Ventilation in calculation of vapour resistance}

Limitations to the methods, when used to calculate vapour resistance, could be posed by the assumptions made about the behaviour of the tracer gas in relation to that of water vapour, in terms of diffusion and convection. Vapour resistance (inversely related to ventilation) can be defined as:

$$
\text { Vapour resistance }=R_{e}=\frac{1}{h_{e, \text { convection }}+h_{e, \text { diffusion }}}
$$

In this equation $h_{e \text {,convection }}$, the convective vapour heat transfer coefficient, is independent of the gas used for the measurement, while $h_{e, \text { diffusion }}$ is dependent on the diffusion constant of the specific gas. Thus the latter will be different between water vapour molecules and other gases used to replace these in the measurement methods.

If 'ventilation' values are low (high resultant $R_{e}$ ), the transport of water vapour or the gas is mainly by diffusion. In that case, the diffusion constant of the molecule is relevant and the data obtained need to be corrected for the difference in diffusion constants between $\mathrm{O}_{2}$ (CR), $\operatorname{Ar}(\mathrm{LH})$ and $\mathrm{H}_{2} \mathrm{O}$. Others (Satsumoto et al., 2008, Satsumoto and Havenith 2010, Sakoi et al., 2008) have also used $\mathrm{CO}_{2}$ and $\mathrm{SF}_{6}$ as tracer gasses, for which the same problem is present, though stronger. The respective diffusion constants relate to that of water vapour in air as $0.74\left(\mathrm{O}_{2}\right), 0.7(\mathrm{Ar}), 0.64\left(\mathrm{CO}_{2}\right)$ and $0.40\left(\mathrm{SF}_{6}\right)$ to 1 . In the past, in the calculation of vapour resistance from ventilation, these correction factors were applied (Havenith et al., 1990), hence assuming diffusion as main transport system. However at higher ventilation values (low $\mathrm{R}_{\mathrm{e}}$ ), when convection is the main pathway the diffusion constant differences between gasses become irrelevant.

A basic model was developed based on equation (4), to calculate the contributions of the diffusion and of the convection part to total mass transport for the different molecules. Using basic assumptions on the clothing, the model predicts the measured vapour resistances for the different tracer gasses and water vapour for different levels of diffusion and convection. Figure 7 and 8 show the relation of the predicted $R_{e}$ 's with Argon, Oxygen, Carbon Dioxide and $\mathrm{SF}_{6}$ to the real vapour resistance for a permeable and an impermeable ensemble. The higher vapour resistances in each graph (around 15mm Still Air Equivalent [SAE; $1 \mathrm{~mm}$ SAE 
$\left.=2.27 \mathrm{~m}^{2} \mathrm{PaW}^{-1}\right]$ for permeable clothing and around 60 to $80 \mathrm{~mm}$ for impermeable clothing) represent the situation where little ventilation takes place, i.e. a static person with no wind present. The lower values represent the same clothing with increasing ventilation, i.e. increasing walking and wind speed (Havenith et al., 1990). The upper box in each graph shows results where the correction for differences in diffusion constant is taken into account. The lower boxes show the relation without any correction. Impermeable garments: The diffusion through the fabric here is negligible, and thus even in the static condition (natural) convection will contribute a relatively large amount to overall moisture transport (in the model calculations, at $80 \mathrm{~mm} \mathrm{SAE}$ [static], $\mathrm{h}_{\mathrm{e}, \text { convective }}$ is 5 times $\left.\mathrm{h}_{\mathrm{e}, \text { diffusion}}\right)$. This indicates that the correction for the different tracer gasses may not be required as evident in Fig. 7. In the lower box, the uncorrected results differ by up to about $10 \%$ for the worst case tracer gas $\left(\mathrm{SF}_{6}\right)$, but with increasing wind/movement convection (moving to lower resultant vapour resistances), the results come closer to the line of unity with errors smaller than $3 \%$ when dynamic vapour resistance drops below $20 \mathrm{~mm}$ SAE. The corrected results however show very large deviations (Fig 7, upper box), which increase with the tracer gasses' difference in diffusion constant relative to that of water vapour.

Permeable garments: The higher diffusion component here (in the model in static conditions

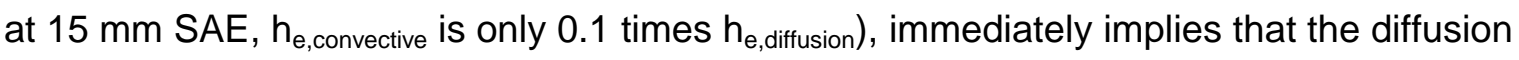
coefficient plays a bigger role here than in the impermeable garment. In static conditions $\left(R_{e}\right.$ around 15-20 mm SAE) the corrected values are close to the actual resistances, while there is a large error in the uncorrected values (Fig. 8). When the dynamic vapour resistance decreases due to movement and wind, the corrected values' error increases however, while, similar to impermeable' the uncorrected error decreases. For the best tracer gasses $\left(\mathrm{O}_{2}, \mathrm{Ar}\right)$ maximal errors for corrected and uncorrected data range between 0 and $25 \%$.

Considering both the model outcomes for impermeable and permeable garments, and taking into account that mostly ventilation is studied in dynamic (wind and movement) conditions, it is evident that the uncorrected test data actually match the dynamic test results across the board. Based on the error analysis the conclusion is that for real life situations where people move and air movement relative to the person is present, both introducing a relevant amount of convection within the clothing microclimate, the errors are expected to be lower than $10 \%$ of the real value and a correction is not relevant given typical errors in vapour resistance measurements (Richards et al, 2005). Only where the whole range of convection-diffusion ratios, including static situations in permeable garments, needs to be covered a correction is needed. As the correction value is not constant (comparing fig. 7 and 8), the model of equation (4) will need to be developed for the specific clothing, estimating the heat transfer 
coefficient for diffusion through the ensemble studied. This value, combined with a range of convection values will indicate how the correction factor changes with the ventilation level.

The ideal tracer gas, which would avoid this issue altogether, is one that has a diffusion constant close to that of water vapour in air. To our knowledge, the ones that come closest are ammonia and methane, both however unsuitable for injection into clothing on humans (though testing with extremely low concentrations of methane may be worth considering).

\subsection{Usability for determination of vapour resistance}

As shown by Havenith et al. $(1990,1999)$ the mass transport indicated by the measured ventilation values can be used to calculate clothing vapour resistance (see also previous section). This was not done before for the CR method. For both methods vapour resistances were calculated according to Havenith et al. (1990), using the corrected volume data for CR. As could be expected, given the ventilation data, vapour resistances for both methods were very similar, except for the highest and lowest ventilations. For the lowest ventilation value (standing still, no wind, manikin), the CR method's vapour resistance increases to over 120 $\mathrm{mm}$ still air equivalent [SAE], whereas the $\mathrm{LH}$ value is around $52 \mathrm{~mm}$. Compared to literature, the latter seems more realistic as a basic value for the 2 piece impermeable ensemble used, suggesting CR underestimates ventilation and overestimates vapour resistance at the low end of the ventilation range. At ventilations above $800 \mathrm{l} / \mathrm{min}, \mathrm{CR}$ and $\mathrm{LH}$ deviate, as discussed before. The vapour resistances are then so low already ( $<3 \mathrm{~mm} \mathrm{SAE}$ ), that the sensitivity of the methods for vapour resistance calculations in this region may be doubted. Unfortunately, reference data for vapour resistance at these high wind and movement speeds are hardly available.

Model calculations by Bentley et al. (2000) have shown that the analysis of the exponential re-entry of $\mathrm{O}_{2}$ in the $\mathrm{CR}$ method can only be used for single layer ensembles, or for those where the outer layer has a far lower air permeability than the inner ones. For the ensembles used here this was no problem, however this should be considered an issue for other applications.

\section{CONCLUSIONS FROM RESEARCH}

Extensive data have been collected on the reproducibility, validity, sensitivity and applicability of different methods for the determination of micro-climate ventilation and vapour resistance. A major problem with the CR method is the determination of MicroClimate Volume using a vacuum-oversuit method. This is laborious and prone to error. Use of 3D body scanning, or an alternative estimation model is proposed instead. When this 
error source in CR is excluded, both the Crockford and the Lotens \& Havenith methods have been shown to be very comparable in their results, sensitivity and validity, except for the extremes of ventilation. Though problems are present in various areas, these are now quantified and this can be used for amendments to the calculations. The major remaining problem for both methods is the effect of the convection/diffusion ratio where the ventilation data are to be used in the calculation of vapour resistance. This problem may be reduced by further research into using different gas types. It is clear however that gasses like $\mathrm{SF}_{6}$ are far from ideal due to the very different diffusion constant from water vapour.

\section{ACKNOWLEDGEMENTS}

This research was funded by the Engineering and Physical Sciences Research Council under Grant number GR/N10509

\section{REFERENCES}

1. Angel, H.A., 1995. Laboratory Studies of clothing ventilation using a direct tracer gas technique and an indirect user performance test, M.Sc. Thesis. Department of Human Sciences, Loughborough University, Loughborough, UK.

2. Bentley, M., Bouskill, L.M., Havenith, G. and Withey, R.W., 2000. Limitations of Using a Single-Exponential Equation for Modelling Clothing Ventilation. Ergonomics of Protective Clothing, Kuklane, K. and Holmér, I. (eds), National Institute for Working Life, Sweden, Nokobetef 6 and 1st European Conference on Protective Clothing, Stockholm, Sweden, May 2000, pp 21-24, ISBN 7045559 7, [WWW] Available from: www.niwl.se/ah/.

3. Birnbaum R.R., Crockford G.W., 1978. Measurement of the clothing ventilation index. Applied Ergonomics, 9(4), 194-200.

4. Bittel, J., Hanniquet, A.M. and Forssard, H., 1992. Thermal constraints related to the wearing of protective clothing: Body ventilation by fresh air. Performance of protective clothing: Fourth Volume, STP 1133, McBriarty, J.P. and Henry, N.W., Eds., ASTM, Philadelphia. 
5. Bouskill, L. M., 1999. Clothing Ventilation and Human Thermal Response; Doctoral Thesis, Loughborough University, dept. Human Sciences.

6. Bouskill, L.M., Havenith, G., Kuklane, K., Parsons, K.C., and Withey, W.R., 2002. Relationship between clothing ventilation and thermal insulation. American Industrial Hygiene Association Journal, 63, 262-268.

7. Brandsma, M., 2001. Body Surface Area determined using a Vitronic 3-D whole body scanner. TNO-report. Soesterberg, The Netherlands.

8. Caravello, V., McCullough, E.A., Ashley, C.D., Bernard, T.E., 2009 Apparent evaporative resistance at critical conditions for five clothing ensembles, European Journal of Applied Physiology 104 (2), 361- 367

9. Crockford, G.W., Crowder, M., Prestidge, S.P., 1972. A trace-gas technique for measuring clothing microclimate air exchange rates. British Journal Industrial Medicine, 29, 378-386.

10. Crockford, G.W., Rosenblum, H.A., 1974. The measurements of clothing microclimate volumes. Clothing Research Journal, 2, 109-114.

11. Daanen, H., Hatcher, K. and Havenith, G., 2002. Determination of Clothing Microclimate Volume , Environmental Ergonomics $X$, The Organizing and International Program Committees of the 10th International Conference on Environmental Ergonomics (eds), The 10th International Conference on Environmental Ergonomics , Fukuoka, Japan, September 2002, pp 66-5668, ISBN 4990135806.

12. Fetcher, E.S., Rapaport, S.I., Hall, J.F. and Shaub, H.G., 1949. Biophysical requirements for the ventilation of clothing. Journal of Applied Physiology, 2(2), 49-60.

13. Ghaddar, N., Ghali, K., Harathani, J., Jaroudi, E., 2005, Ventilation rates of microclimate air annulus of the clothing-skin system under periodic motion, International Journal of Heat and Mass Transfer, Volume 48, Issue 15, July 2005, Pages 3151-3166.

14. Ghali, K., Ghaddar, N., and Jones, B., 2002, Modelling of heat and moisture transport by periodic ventilation of thin cotton fibrous media, International Journal of Heat and Mass Transfer, Volume 45, Issue 18, August 2002, Pages 3703-3714.

15. Ghali, K., Othmani, M., Jreije, B., Ghaddar, N. (2009) Simplified Heat Transport Model of a Wind-permeable Clothed Cylinder Subject to Swinging Motion, Textile Research Journal 2009 79: 1043-1055 
16. Harter, K.L., Spivak, S.M. \& Yeh, K., 1981. Applications of the trace gas technique in clothing comfort. Textile Research Journal, 1981, 51, 345-355.

17. Hatcher, K., 2001. Different Methods For Evaluating Microclimate Volume: A Comparison Study, Msc Thesis, Loughborough University.

18. Havenith, G., Heus, R., Lotens, W.A., 1990. Clothing ventilation, vapour resistance and permeability index: changes due to posture, movements and wind. Ergonomics, 33, 8, 989-1005.

19. Havenith, G., Vuister, R., Wammes, L.J.A., 1996. The effect of clothing air permeability of chemical protective clothing material on clothing vapour resistance. In: Y. Shapiro, D.S. Moran, Y. Epstein (Eds.) Environmental Ergonomics Recent Progress and new frontiers, 213-217. London and Tel Aviv: Freund Publishing House, Ltd.

20. Havenith, G., 1999 Heat balance when wearing protective clothing, Annals of Occupational Hygiene, 43, 5, 289-296.

21. Havenith, G., Holmér, I. Den Hartog, E.A., Parsons, K.C., 1999. Clothing evaporative heat resistance - proposal for improved representation in standards and models, Annals of Occupational Hygiene, 43, 5, 339-346.

22. Havenith, G., 2002. The interaction between clothing insulation and thermoregulation; Exogenous Dermatology, 1(5) 221-230, 2002

23. Havenith, G., Ueda, H., Sari, H., and Inoue, Y., 2003. Required clothing ventilation for different body regions in relation to local sweat rates, in: Proceedings 2nd European Conference on Protective Clothing (ECPC), "Challenges for Protective Clothing" 21 24 May 2003, Montreux, Switzerland.

24. Havenith, G., 2005. Clothing Heat Exchange Models For Research And Application. In: The 11th International Conference On Environmental Ergonomics, Ystad, Sweden; Proceedings published as Environmental Ergonomics 2005. Editors I Holmér, K Kuklane and C Gao. Lund University, Lund, Sweden, 2005.ISBN 91-631-7062-0, 66-73.

25. Havenith, G., Richards, M., Wang, X., Bröde, P., Candas, V., den Hartog, E, Holmér, I., Kuklane, K., Meinander, H. and Nocker, W., 2008. Apparent latent heat of evaporation from clothing: attenuation and "heat pipe" effects, J Appl Physiol, 104: 142 - 149., doi:10.1152/japplphysiol.00612.2007. 
26. Holland, E.J., Wilson, C.A., Laing, R.M., Niven, B.E., 1999. Microclimate ventilation of infant bedding. International Journal of Clothing Science and Technology, Vol. 11 No. 4, 1999, pp.226-239.

27. ISO 9920, 2007. Ergonomics of the thermal environment - Estimation of thermal insulation and water vapour resistance of a clothing ensemble; International Organisation for Standardisation, Geneva.

28. ISO 11092, 1993. Textiles - Determination of physiological properties - Measurement of thermal and water vapour resistance under steady-state condition (sweating guarded -hotplate), International Organisation for Standardisation, Geneva.

29. Lee, Y., Hong, K., Hong, S. A., 2007. 3D quantification of microclimate volume in layered clothing for the prediction of clothing insulation. Applied Ergonomics, 38, 3, 349-355.

30. Lotens, W.A., Havenith, G., 1988. Ventilation of rainwear determined by a trace gas method. In: Environmental Ergonomics, Editors: Mekjavic, Bannister, Morrison; Philadelphia, Taylor and Francis, 162-175.

31. Lotens, W.A., Havenith, G., 1991. Calculation of clothing insulation and vapour resistance. Ergonomics 34, 2, 233-254.

32. Reischl, U., Stransky, A., 1980. Assessment of ventilation characteristics of standard and prototype fire-fighter protective clothing. Textile Research Journal, 50, 193-201.

33. Reischl, U., Spaul, W.A., Dukes-Dobos, F.N., Hall, E., 1987. Ventilation analysis of industrial protective clothing In: Trends in Ergonomics/Human Factors IV . Editors: S.S. Asfour; North- Holland, Elsevier Science Publishers B.V., 421-428.

34. Richards, M. G. M., Mccullough, E. A., 2005. Revised Interlaboratory Study of Sweating Thermal Manikins Including Results from the Sweating Agile Thermal Manikin, ASTM special technical publication - 2005, 1462, 27-39.

35. Sakoi, T., Zhu, S., Tsuzuki, K., Kato, S., Ooka, R., and Tamura, T., 2008. Estimation of Ventilation and Ascending Air Flow by Heat inside Clothing, 7th International Thermal Manikin and Modelling Meeting - University of Coimbra, September 2008

36. Satsumoto, Y., Takeuchi, M., Habu, C., Yoshizaki, A., Imamura, Y., Wada, M., Akaki, K., Miyazawa, K., 2008. Development of device to evaluate the ventilation of diaper. 2008 Korea-Japan Joint Conference on Wellness@Living Environment. 
37. Satsumoto, Y. and Havenith G., 2010. Evaluation of overall and local ventilation in diapers, submitted to Textile Research Journal.

38. Shivers, J.L., Yeh, K., Fourt, L. and Spivak, S.M., 1977. The effects of design and degree of closure on microclimate air exchange in lightweight cloth coats. In: Clothing Comfort: Interaction of thermal, ventilation, construction and assessment factors. Norman R.S. Hollies and Ralph F. Goldman (eds.).

39. Sullivan, P.J., Mekjavic, I.B., Kakitsuba, N., 1987. Determination of clothing microclimate volume. Ergonomics 30, 7, 1043-1052.

40. Tan, K., and Daanen, H., 1999. Calibration of the Vitronic 3-D Scanner, TNO-rapport, Soesterberg, The Netherlands.

41. Ueda, H., and Havenith, G., 2005. The effect of fabric air permeability on clothing ventilation, in: Environmental Ergonomics, Tochihara, Y. and Ohnaka, T. (eds); Elsevier.

42. Ueda, H., Inoue, Y., and Havenith, G., 2005. The Influence Of A Back Opening On Clothing Ventilation In Rainwear. In: Environmental Ergonomics, The 11th International Conference On Environmental Ergonomics, Ystad, Sweden; Editors I Holmér, K Kuklane and C Gao. Lund University, Lund, Sweden, 2005.ISBN 91-631-7062-0, 411415.

43. Ueda, H., Inoue, Y., Matsudaira, M., Araki, T., and Havenith, G., 2006. Regional microclimate humidity of clothing during light work as a result of the interaction between local sweat production and ventilation, International Journal of Clothing Science and Technology, 18-4, 225-234.

44. Vokac, Z., Kopke, V., Keul, P., 1973. Assessment and analysis of the bellows ventilation of clothing, Textile Research Journal, 43, 8, 474-482. 
Table 1: Repeatability of measurements expressed as coefficient of variation for the different experiments with the 4 clothing ensembles. ${ }^{1}$ The Crockford data do not include variations present in the microclimate determinations; a single (average) value was used for microclimate volume in the ventilation calculations.

\begin{tabular}{|c|c|c|c|}
\hline \multirow[t]{2}{*}{ Experiment } & \multirow{2}{*}{$\begin{array}{l}\text { Range of } \\
\text { Ventilations } \\
(1 / \mathrm{min})\end{array}$} & Crockford method $^{1}$ & Lotens / Havenith \\
\hline & & \multicolumn{2}{|c|}{ Coefficient of variation (min-max) (\%) } \\
\hline 1-Forced ventilation & $0-200$ & $1.5(0.7-3.5)$ & $2.3(0.8-5.1)$ \\
\hline 2-Manikin, wind & $5-1400$ & $3.4(0.6-7.9)$ & $3.4(0.8-9.7)$ \\
\hline $\begin{array}{l}\text { 3-Human, standing, no } \\
\text { wind }\end{array}$ & $15-280$ & $5.6(4.9-6.7)$ & $6.3(1.6-8.9)$ \\
\hline $\begin{array}{l}\text { 3-Human, standing, } \\
\text { wind }\end{array}$ & $93-1330$ & $13.7(7.5-17.2)$ & $9.1(6.1-15.0)$ \\
\hline $\begin{array}{l}\text { 3-Human, walking, no } \\
\text { wind }\end{array}$ & $47-350$ & $3.2(2.5-4.9)$ & $4.2(1-6.1)$ \\
\hline 3-Human, walking, wind & $91-1380$ & $8.0(3.2-13.3)$ & $7.1(1-13.3)$ \\
\hline
\end{tabular}




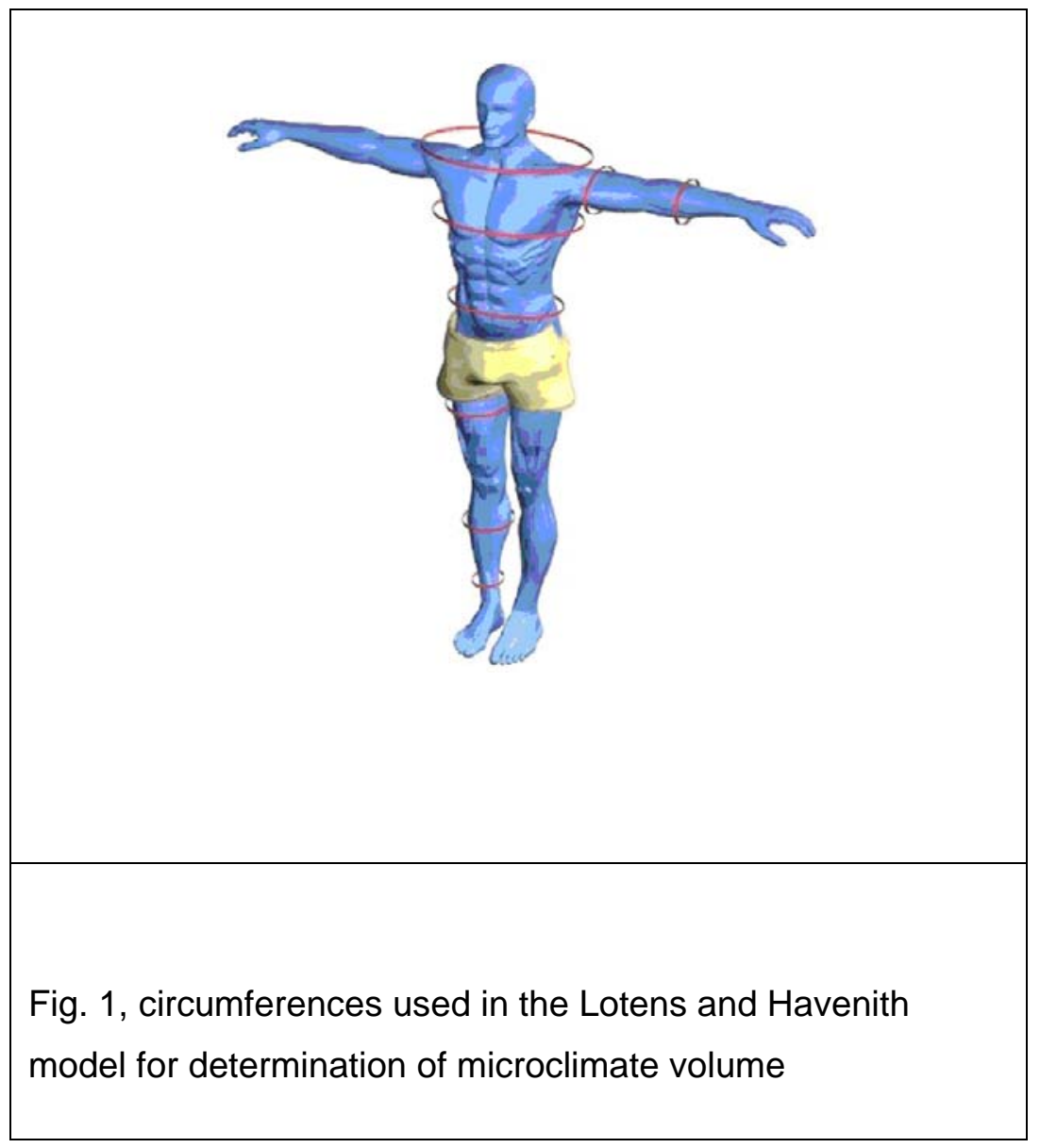



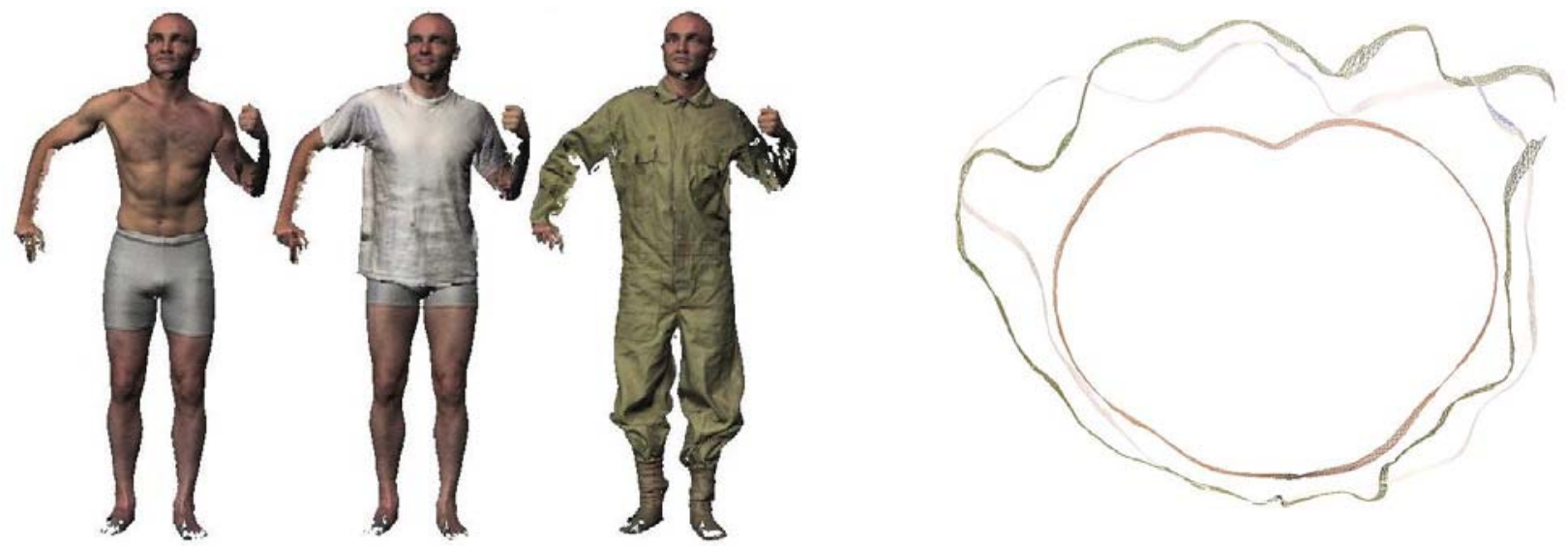

Fig. 2 Frontal and transversal view of the scans for subject 1. The inner object is the torso, the thin line is the T-shirt and the thick line is the coverall. Note that the folds are well covered by the scanner. 


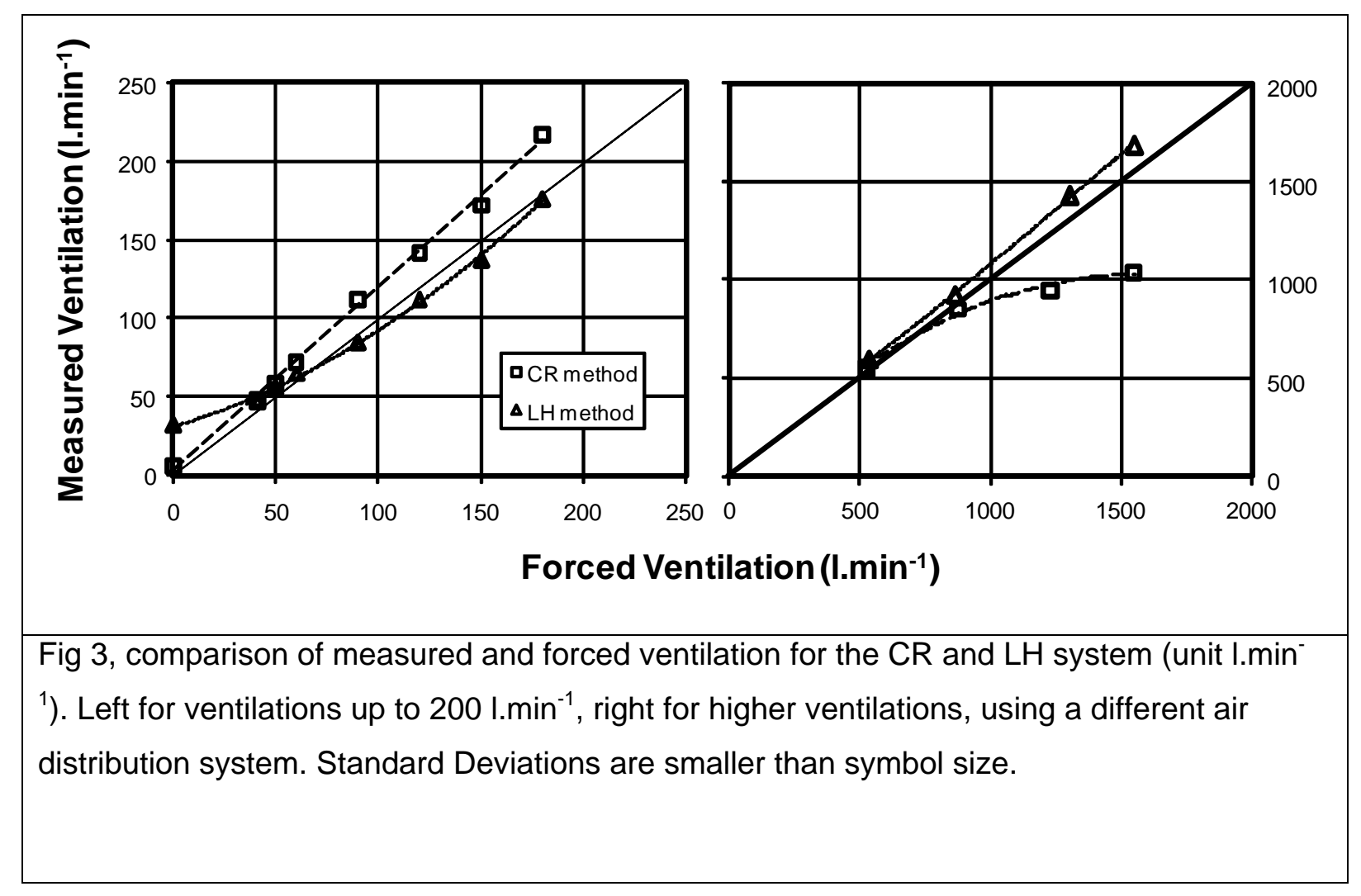




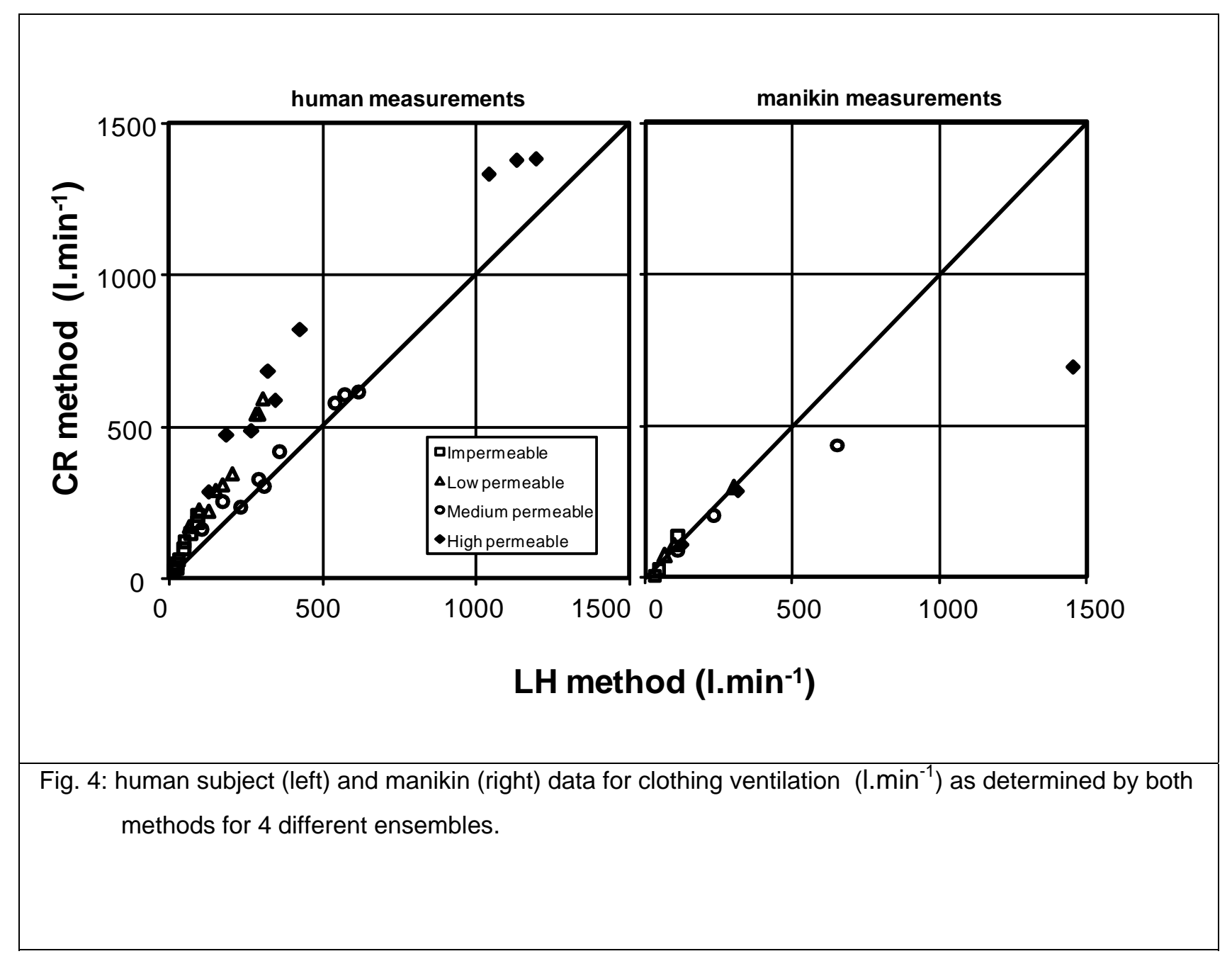




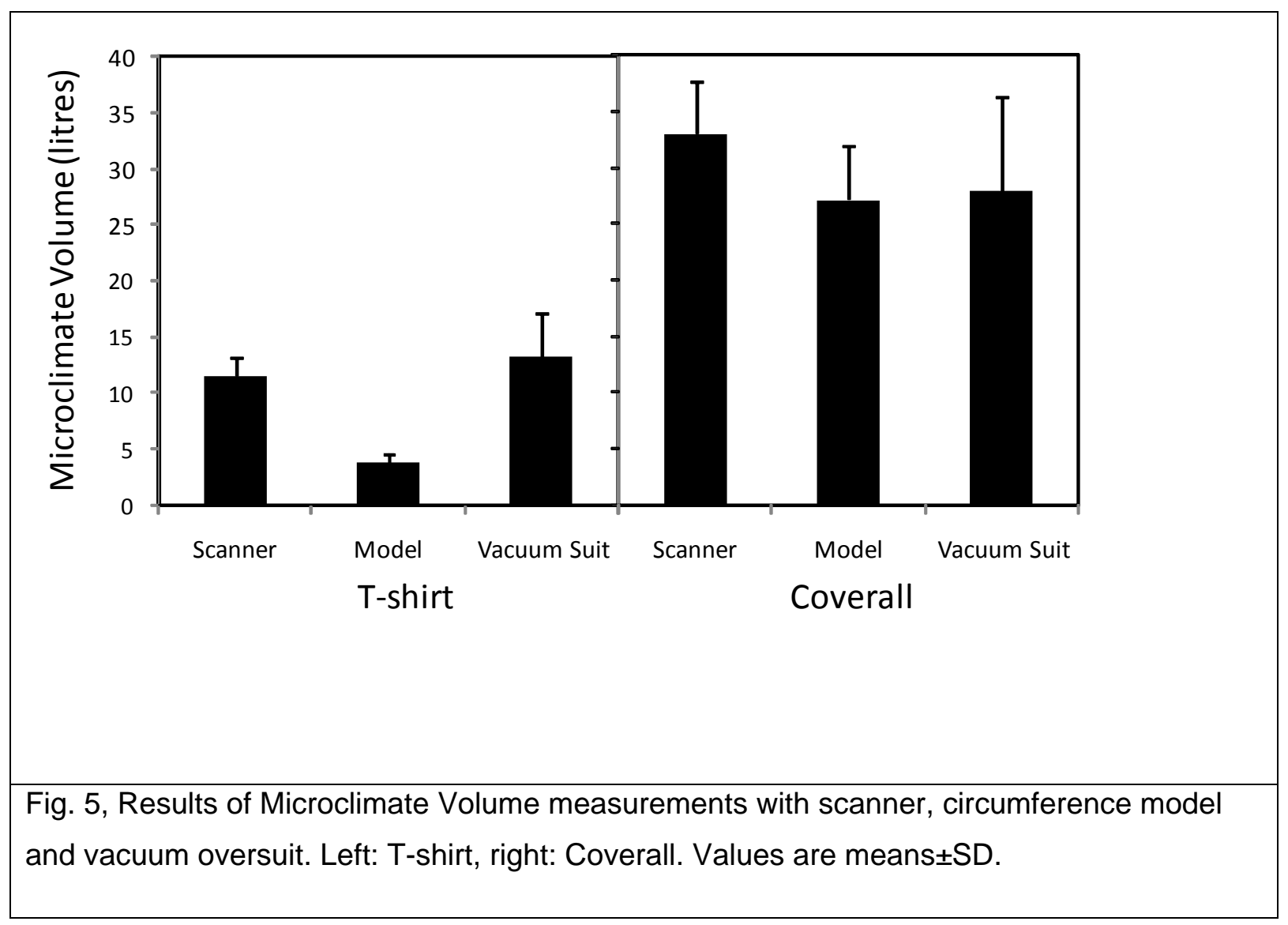




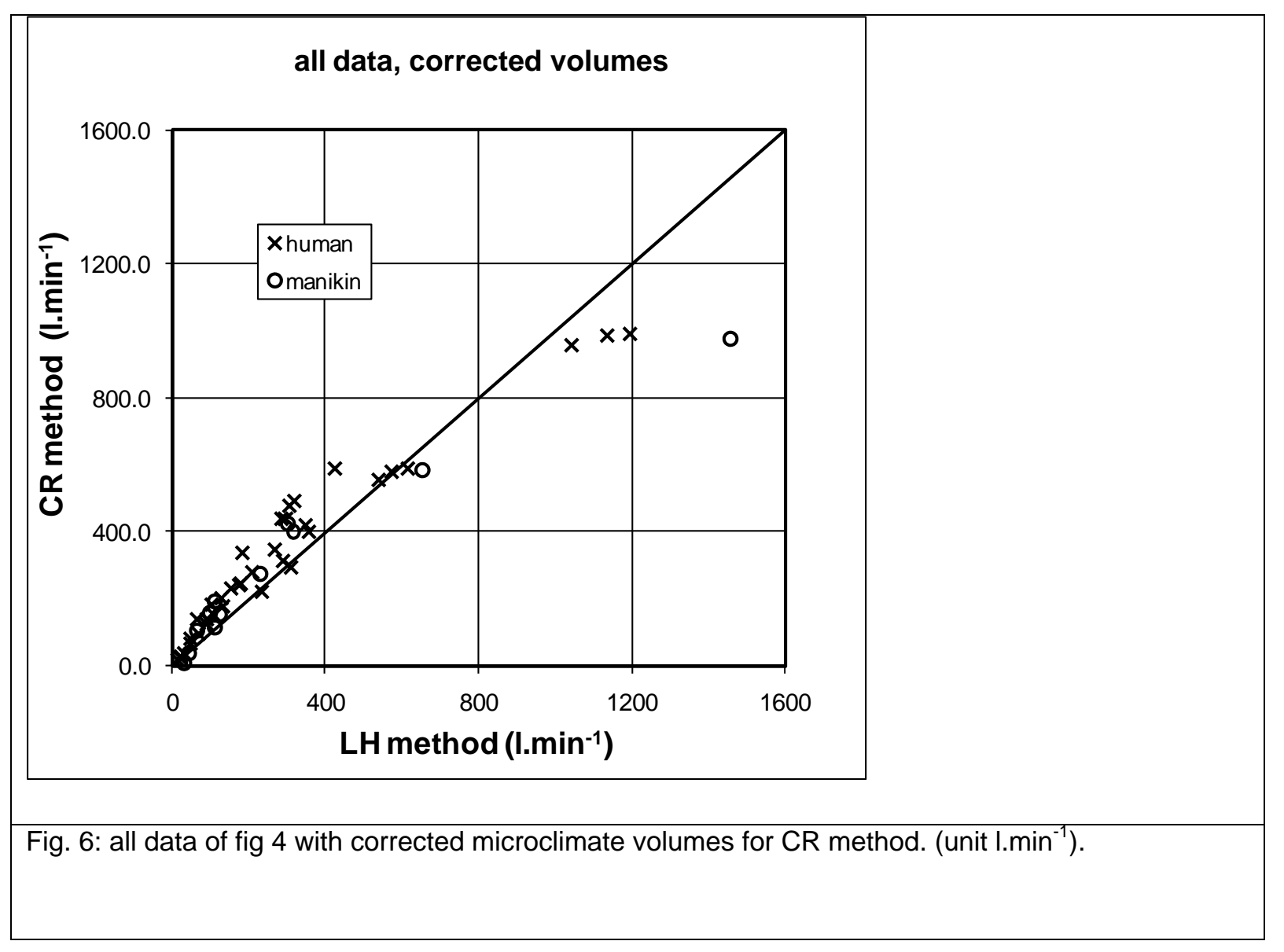




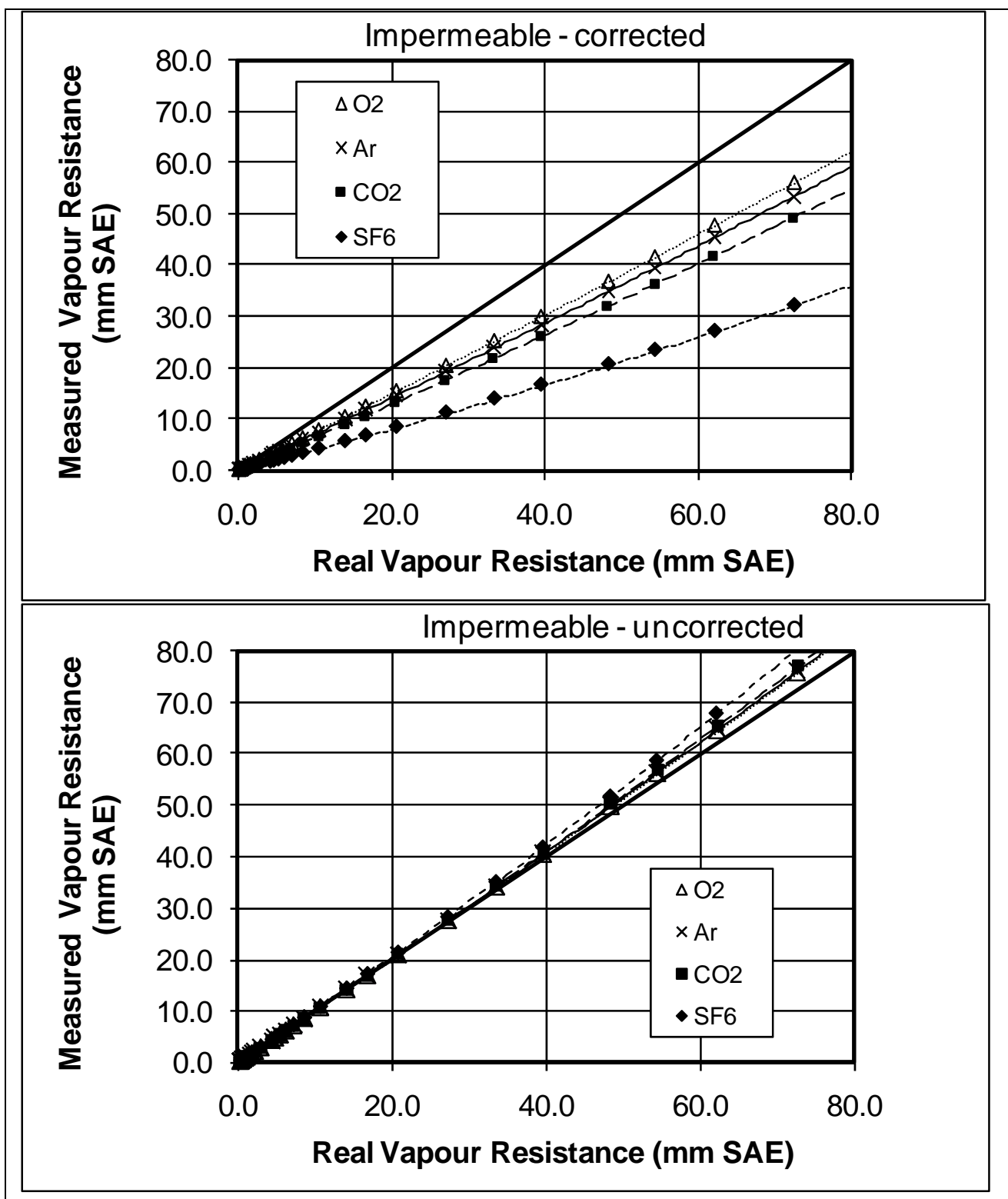

Fig. 7, 'Measured' versus real vapour resistance based on a model simulation calculation for an Impermeable ensemble Top: if a correction for diffusion constants of different gasses is applied; bottom: without applying a correction. SAE=Still Air Equivalent; $1 \mathrm{~mm}$ SAE $=2.27$ $\mathrm{m}^{2} \mathrm{PaW}^{-1}$ 


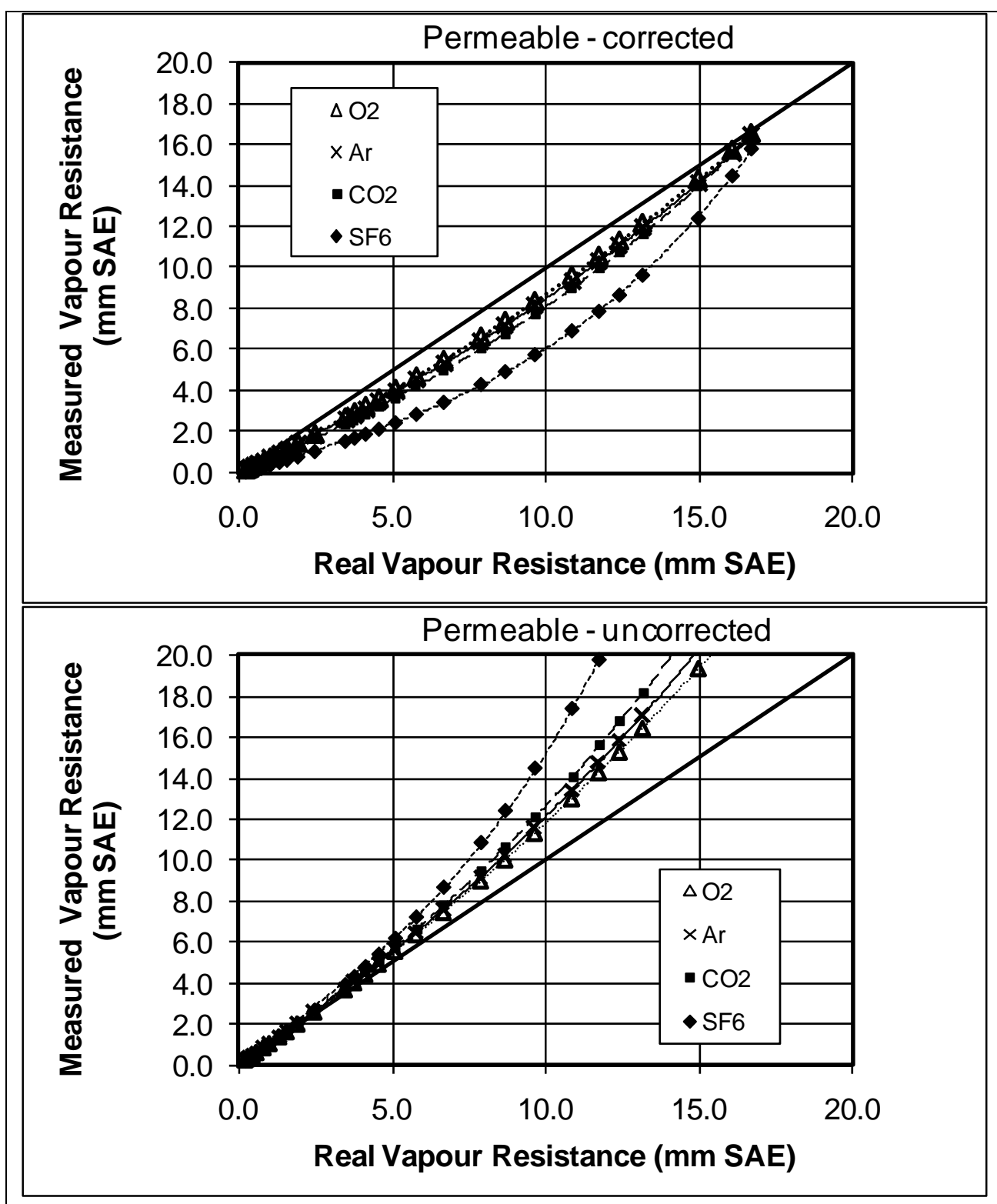

Fig. 8, 'Measured' versus real vapour resistance based on a model simulation calculation for a Permeable ensemble. Top: if a correction for diffusion constants of different gasses is applied; bottom: without applying a correction SAE=Still Air Equivalent; $1 \mathrm{~mm} \mathrm{SAE}=2.27$ $\mathrm{m}^{2} \mathrm{PaW}^{-1}$ 